\title{
Academics for dental primary care
}

\author{
F. J. T. Burke, ' and M. E. Pendlebury, ${ }^{2}$
}

\section{Driven by the need to address integrated dental care, many UK dental schools have recognised the advantages of teaching dental practice, or dental primary care (DPC), as a separate and defined subject area.' In such schools, DPC may be taught alongside specialist subjects such as restorative dentistry, oral surgery, oral medicine and those traditionally forming elements of the dental undergraduate curriculum. As a result, departments or units of general dental practice or DPC have been established.}

\begin{abstract}
The objectives of general dental practice 1 or DPC departments and units include the integration of the teaching and knowledge gained in specialist disciplines so that the planning and completion of the holistic care of patients is possible in a manner similar to that applied in general dental practice. Additional objectives for the student may include:
\end{abstract}

- Improving patient management and gaining an awareness of time use, understanding the role of audit

- Learning some management skills, and

- Appreciating the value of research in dental practice and its relevance to 'evidence-based dentistry', while at the same time learning to integrate the skills and knowledge learnt in specialist treatment areas.

These are skills which the undergraduate should begin to acquire in dental school, to be enhanced during vocational training and subsequently during career development.

However, it is more difficult to recreate the continuum of care that is an essential feature of primary care. It may also be difficult to teach the undergraduate aspects of DPC, such as audit or how to become the leader of a dental team with the associated management and administrative skills, not

\footnotetext{
${ }^{1}$ University of Birmingham School of Dentistry, St.Chad's Queensway, Birmingham B4 6NN, UK ${ }^{2}$ Past Dean, Faculty of General Dental Practitioners, Royal College of Surgeons of England, Lincoln's Inn Fields, London WC2A 3PN

${ }^{*}$ Correspondence to F. J. T. Burke

e-mail:f.j.t.burke@dental.gla.ac.uk

REFEREED PAPER

Received 09.05.00; Accepted 06.10.00

(C) British Dental Journal 2001; 191: 64-65
}

only because of course time constraints, but also because these subjects may be considered more appropriate to the general dental practice arena. The student should, however, acquire the ability to critically appraise the literature and understand the concept of evidence-based dentistry.

Dental practice units may be held in a separate building from the main dental

\section{An essential element of the background for the academic in DPC should be experience in general dental practice: there can be no substitute}

hospital or school, or alternatively they may be taught in clinics normally used for teaching other subjects, which are adapted and equipped so that all forms of treatment may be carried out. ${ }^{1}$

\section{Career pathways}

Career pathways are well developed for those wishing to pursue subjects traditionally offered in academic or hospital dentistry and career pathways have recently been produced for 'high street' specialist practice. However, it is still to be determined how this concept will function in general practice. The requirements for specialist status, and subsequent appointment to the consultant grade, are generally well defined. Similarly, for a senior academic appointment most academic institutions require a research qualification (preferably a doctorate), the publication of a specified number of papers in peerreviewed journals, international study, funded research and future potential. It would be expected that the new discipline of academic DPC would have similar requirements. There are difficulties, however, in obtaining many of these requirements while still working as a general dental practitioner, which is an essential component of an academic in DPC. A review of senior positions in UK dental practice units has shown that these are held by persons with qualifications varying from a basic dental degree to multiple degrees including Masters of Science degrees, Doctorates, Masters in Business Administration and/or Fellowships of a Royal Surgical Colleges. This may not be considered surprising, given that no guidelines have previously existed for such appointments other than, perhaps, some experience of general dental practice.

It may be expected that up-and-coming academics may wish to consider academic DPC as a career option. Guidelines for such future academics in DPC are therefore required. It may be considered that dental practice should be built around a restorative framework - given that the dental practitioner spends much of her or his time either carrying out restorative dentistry or deciding whether such intervention is necessary. However, a purely restorative background would prove inadequate, given the need for knowledge of areas such as oral surgery, paediatric dentistry, preventive dentistry, treatment of the elderly and the anxious. Furthermore, in general dental practice these treatments take place in a setting where time means money, staff require management and regulations, laws and local bureaucracy require compliance. Therefore, an essential element of the background for the academic in DPC should be experience in general dental practice: there can be no substitute. It would also seem reasonable to suggest that this general dental practice experience included appointment as a principal and probably for a 
minimum of six years (this being sufficient time to allow the candidate to have achieved, for example, MGDS). Ideally, such experience in practice should continue throughout that dentist's academic career, either in their own practice or by the establishment of 'teaching' practices. Such practices could form the basis for teaching in DPC - outreach teaching as termed by the GDC. ${ }^{2}$ Such 'teaching' practices could act as centres for research, as has been the case in general medical practice, and could be of value in postgraduate education. Additionally, the candidate for senior posts in academic DPC should hold a research qualification, given that such persons should have an awareness of the benefits of practice-based research. ${ }^{3}$ This experience could also act as a catalyst for those in practice who may wish to develop research ideas. Similarly, some experience of publication in peer-reviewed journals would appear to be of benefit.

For much of the past fifty years the accepted qualification for a consultant position in the UK has been a Fellowship in Dental Surgery. However, it would seem unreasonable for the academic in DPC to have obtained what is, essentially, a hospital-based qualification. Arrangements are changing to bring the UK into line with European regulations for specialists. The future specialists will require a Membership Diploma of a UK Royal College in their specialist subject, plus a period of training in the specialty (eg FDS Orth). It would therefore seem reasonable to expect that future academics in DPC should hold an MGDS diploma, a broadly-based qualification intended to indicate excellence in general dentistry. The recently published Faculty of General Dental Practitioners (UK) career development pathway describes a modular approach to training extending over a number of years. ${ }^{4}$ The training modules will be available in the major divisions of dentistry, having at their core a module of primary dental healthcare management. The pathway is based on the principles of flexibility and assessed prior learning. The MGDS will become more attainable through this route without any diminution of its mea- sure of clinical excellence. The FGDP (UK) pathway, similar to the other specialties, peaks at the Fellowship level. This is a demonstration of clinical ability in action. It is also now possible for practitioners with an MGDS to take an FDS (RCS Edin) by Assessment five years after completing the MGDS. However, when examining this

\section{Future academics in DPC should hold an MGDS diploma, a broadly-based qualification intended to indicate excellence in general dentistry}

career pathway, it should be remembered that at present such a pathway is optional for the GDP. This is in contrast to those working in a hospital or academic environment, for whom a well-defined career pathway must normally be followed if promotion from one level to another is to be achieved. This achievement of postgraduate qualifications for the GDP should always be viewed with this comment in mind.

A number of institutions have introduced, or are considering the introduction of, Masters' degree programmes in DPC. Others have introduced distance learning programmes, aimed specifically at the busy dental practitioner. These courses and qualifications may also be considered to contribute strongly to the practitioner's career development. It may be possible that, in the future, these qualifications could provide exemption from some part of a diploma such as MGDS.

An alternative for those who have altered their career pathway from the hospital or academic environment to general dental practice could be a Membership Diploma in Restorative Dentistry, given the emphasis on restorative dentistry in most dental practices, plus experience in general dental practice. The completion of the healthcare management module of the FGDP would be desirable for these aspirants.

It would be incorrect to conclude without mention of the Community Dental Service, given the involvement of this service in DPC, although often for different population groups than those seen in many general dental practices. Their training pathway has developed substantially in the past decade, and it could be considered that the switch from the Community Dental Service to academic DPC could be easily made. Similar qualifications could apply in respect of research and publications but with a community diploma instead of an MGDS.

In summary, it would appear ideal that the academic should have achieved MGDS and desirably a Fellowship (FFGDP [UK] or FDS [Edin]) as this implies substantial experience in dental practice. A significant number of publications in peer-reviewed journals is an obvious requirement, with a formal research qualification being desirable.

McLaughlin has suggested that around one-quarter of clinical dental academic staff should be taken from the community of successful practising dentists. ${ }^{5}$ It would appear appropriate at this time to commence discussions concerning the requirements for those aspiring to be the future teachers of academic DPC. Therefore, those hoping to follow such a career may be aware of what coulc be required of them academically in the same way that those aspiring to a hospital or academic career are aware of what qualifications are normally required for the various stages of their career.

1. Burke F J T, Jenson L, McHugh S, Wilson N H F. Teaching of comprehensive patient care in dental schools in the US, UK and Ireland. Paper submitted for editorial consideration.

2. General Dental Council. The First Five Years London: The General Dental Council, 1997.

3. Burke F J T, McCord J F. Research in general dental practice: problems and solutions. $\mathrm{Br}$ Dent J 1993; 175: 396-398.

4. Lambert-Humble S. FGDP(UK) Career Pathway for General Dental Practitioners. First Hand. April 2000: p1-3.

5. McLaughlin G. What makes a good dental school? Br Dent J 1996; 181: 274-275. 